\title{
Dispersive liquid-liquid microextraction for the preconcentration and spectrophotometric determination of copper(II) in blood serum sample using sodium diethyldithiocarbamate as the complexing agent
}

\author{
Reza Emamali Sabzi ${ }^{1}$, Naimeh Mohseni ${ }^{1}$, Morteza Bahram ${ }^{1}{ }^{*}$, Mahmoud Rezazadeh Bari $^{2}$ \\ ${ }^{1}$ Department of Chemistry, Faculty of Science, Urmia University, Urmia, Iran \\ ${ }^{2}$ Department of food science and technology, Faculty of agriculture, University of Urmia, Urmia, Iran
}

\begin{abstract}
A dispersive liquid-liquid microextraction (DLLME) process based on the complexation reaction of $\mathrm{Cu}$ (II) with diethyldithiocarbamate (DDTC) from aqueous solutions was investigated. The effect of various experimental parameters in the extraction such as, dispersive solvent, extracting solvent, the volume of extraction and disperser solvent, $\mathrm{pH}$ of the aqueous solution, ionic strength and extraction time were optimized using one variable at a time method, and the analytical charactristics of the method were obtained. Under the optimum conditions the calibration graph was linear over the range 0.01 to $0.1 \mu \mathrm{g} \mathrm{mL}^{-1}$ of $\mathrm{Cu}(\mathrm{II})$ ion with a correlation coefficient of 0.994 . The limit of detection $(\mathrm{S} / \mathrm{N}=3)$ was $8.6 \times 10^{-3} \mu \mathrm{g} \mathrm{mL}^{-1}$. Relative standard deviation (RSD) for 7 replicate determinations of $0.08 \mu \mathrm{g} \mathrm{mL}{ }^{-1} \mathrm{Cu}(\mathrm{II})$ was $3.3 \%$. In this work, the concentration factor of 20 and also the improvement factor of 33 were reached. The interference effect of some anions and cations was also tested. The extraction method has been successfully applied to the determination of copper in human blood serum sample.
\end{abstract}

Keywords: Copper; Sodium diethyldithiocarbamate; Dispersive liquid-liquid microextraction; Spectrophorometric determination; Blood serum sample.

\section{Introduction}

Copper is an essential micronutrient that has a crucial role in a variety of biological processes indispensable to sustain life ${ }^{1}$. At the same time, higher concentrations of copper can be toxic and cause stomach and intestinal distress, liver and kidney damage, and anemia. The US Environmental Protection Agency (USEPA) and the World Health Organization (WHO) recommended maximum allowable concentration of 1.3 and $2 \mathrm{mg} \mathrm{dm}^{-3}$, respectively for copper in drinking water ${ }^{2,3}$. Since it has had numerous applications in the industry, copper pollution in the environment can occur that may cause toxic effects to living organisms in natural waters or humans. Therefore, circulating levels of this metal in the plasma must be kept under tight regulation.

The direct determination of heavy metals including copper at trace levels using various modern instrumental methods including flame atomic absorption spectroscopy (FAAS),

*Corresponding author: Morteza Bahram

E-mail address: m.bahram@urmia.ac.ir

DOI: http://dx.doi.org/10.13171/mjc.3.6.2015.01.10.14.50 
inductively coupled plasma-optical emission spectrometry (ICP-OES) and inductively coupled plasma-mass spectrometry (ICP-MS) has been unsuccessful due to particularly their low concentrations and matrix effects. However, preconcentration and matrix elimination is usually required for the determination of low concentrations of the metal ions in environmental samples ${ }^{4}$.

Various preconcentration and separation methods such as, liquid-liquid extraction $(\mathrm{LLE})^{5-8}$, cloud point extraction $(\mathrm{CPE})^{9-12}$, solid phase extraction (SPE) ${ }^{13-16}$, ion exchange ${ }^{17}$ and co-precipitation ${ }^{18,19}$ hyphenated with different detection techniques, have been applied for extraction of trace levels of the heavy metal ions including copper(II) from different biological and environmental samples. However, some of these methods suffer from inconveniences such as, lengthy separation, limitation of the volume of sample solution investigated, time consuming, multi stage, yielding unsatisfactory preconcentration factors and the use of large quantities of organic solvents.

In 2006, Assadi and co-workers developed a novel liquid phase microextraction technique, named dispersive liquid-liquid microextraction (DLLME) ${ }^{20,21}$. It is a simple and fast microextraction technique based on ternary component solvent systems. This method needs microliter volumes of extraction solvents and little amounts of a disperser solvent. The extraction solvent is an organic solvent such as chlorobenzene, chloroform or carbon disulfide with high density and the disperser solvent is an organic solvent, such as methanol, acetone or acetonitrile that is miscible with both extraction solvent and water. When the mixture of extraction phase and disperser is rapidly injected into the sample, a cloudy solution is formed. Since the surface area between the extracting solvent and the aqueous sample is very large, thus the equilibrium state is achieved quickly and the extraction is independent of time. In fact, this is the main advantage of DLLME. After centrifugation, the fine particles of extraction solvent sedimented in the bottom of the conical test tube. The sedimented phase is removed manually by a syringe and analyzed by various analytical techniques including, high-performance liquid chromatography (HPLC) $^{22}$, electrothermal atomic absorption spectrometry (ET-AAS) ${ }^{23-25}$ FAAS $^{26-29}$, ICP-OES ${ }^{30}$, spectrophotometric analysis ${ }^{31,32}$ and energy-dispersive X-ray fluorescence spectrometry ${ }^{33}$.

Diethyldithiocarbamate (DDTC) is a classical bidentate ligand that forms complexes with many metal ions including $\mathrm{Cu}^{2+}, \mathrm{Co}^{2+}$ and $\mathrm{Ni}^{2+}$. The complexing properties of this ligand is directly connected with the presence of two donor sulphur atoms (Scheme 1$)^{34}$. DDTC metal complexes are insoluble in water but soluble in organic solvents, therefore a solventextraction step is necessary.

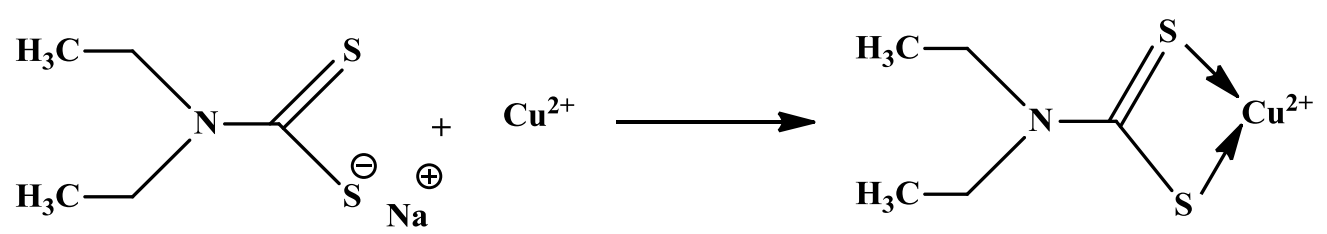

Scheme 1. Chemical structure of sodium diethyldithiocarbamate in its free and complexed form.

$\mathrm{X}$.Wen et $\mathrm{al}^{35}$ have applied dispersive liquid-liquid microextraction combined with UV-vis spectrophotometry for determination of cadmium and copper in water and food samples. The limit of detection in this work for $\mathrm{Cu}$ (II) determination was reported as $0.5 \mu \mathrm{g} \mathrm{L}^{-1}$. 
In this report, dispersive liquid-liquid microextraction method has employed for the preconcentration and spectrophotometric determination of $\mathrm{Cu}$ (II) using DDTC as the complexing agent. The most important aim of this work was clearly study of the related parametrs in dispersive extraction method. In the previous work ${ }^{35}$ the calculated LODs for two studied cations were very ambiguous. Also in proposed method the applicability of DLLME for determination of $\mathrm{Cu}(\mathrm{II})$ in human plasma was studied. The experimental parameters were optimized using one variable at a time method. The proposed method is simple, efficient and rapid and it uses extracting solvent at a microliter level. Furthermore, a well-known and cheap ligand diethyldithiocarbamate was utilized. The extraction method has been successfully applied to the determination of $\mathrm{Cu}$ (II) in blood serum sample.

\section{Experimental Section}

\section{Reagents}

All experiments were performed with analytical reagent grade chemicals. All chemicals such as sodium diethyldithiocarbamate, methanol, ethanol, chloroform, dichloromethane, acetonitrile and tetrahydrofuran were obtained from Merck (Darmstadt, Germany) and used without any purification. Individual stock solution of $\mathrm{Cu}$ (II) at a concentration of $1000 \mu \mathrm{g} \mathrm{mL}^{-1}$ was prepared by dissolving appropriate amount of salt in distilled water. Standard solution of $1 \mu \mathrm{g} \mathrm{mL} \mathrm{m}^{-1} \mathrm{Cu}$ (II) was prepared daily by a suitable dilution of stock solution with distilled water. Sodium diethyldithiocarbamate $0.05 \mathrm{M}$ was prepared in distilled water. Acetate buffer $(\mathrm{pH}=5)$ was used for $\mathrm{pH}$ adjustment.

\section{Apparatus}

UV-visible spectra were measured by using Shimadzu UV-2550 double-beam spectrophotometer with $1-\mathrm{cm}$ quartz cells. Phase separation was assisted using UrumTadjihiz centrifuge (Urmia, Iran) centrifuge. A Metrohm model $713 \mathrm{pH}-$ meter with a combined glass electrode was used for $\mathrm{pH}$ measurements.

\section{General analytical procedure}

Appropriate amount of $\mathrm{Cu}$ (II) solution was transferred into a $12 \mathrm{~mL}$ test tube with conical bottom, $1 \mathrm{~mL}$ acetate buffer and $1 \mathrm{~mL}$ DDTC solution were added. By using a 5-mL syringe, $1 \mathrm{~mL}$ methanol containing $200 \mu \mathrm{L}$ chloroform was added to the above solution. Chloroform was dispersed in all parts of sample and no need to homogenize the sample. The mixture was immediately centrifuged for $5 \mathrm{~min}$ at $1000 \mathrm{rpm}$. The sedimented phase was quantitatively transferred to another test tube and allowed to evaporate at room temperature. Finally the residue was diluted with $0.5 \mathrm{~mL}$ ethanol and its absorbance was measured at $440 \mathrm{~nm}$.

\section{Analysis of blood serum samples}

Blood sample was taken from a healthy volunteer, centrifuged at $3000 \mathrm{rpm}$ for $10 \mathrm{~min}$ and serum fractions were collected. Precipitation of proteins was carried out by adding phosphoric acid $\left(2 \mathrm{~mol} \mathrm{~L}^{-1}\right)$ to the serum sample. The $\mathrm{pH}$ of the samples was adjusted at 5. $1 \mathrm{~mL}$ methanol and $200 \mu \mathrm{L}$ of tetracholoride carbon were added to the samples. The tube was centrifuged for 5 minutes and the clear supernatant liquid was used. Samples of the supernatant liquid (each of $2 \mathrm{~mL}$ ) were fortified with various concentrations of $\mathrm{Cu}$ (II). Then the analysis was followed up as indicated in the general analytical procedure. 


\section{Results and Discussion}

Figure 1 shows the absorption spectra for the individual metal complex in organic phase against reagent blank. The addition of an aqueous solution of DDTC to a slightly acidic solution of $\mathrm{Cu}$ (II) ion produces a brown colloidal suspension of $\mathrm{Cu}$ (II)-DDTC which is water insoluble but easily dissolved in several organic solvents.

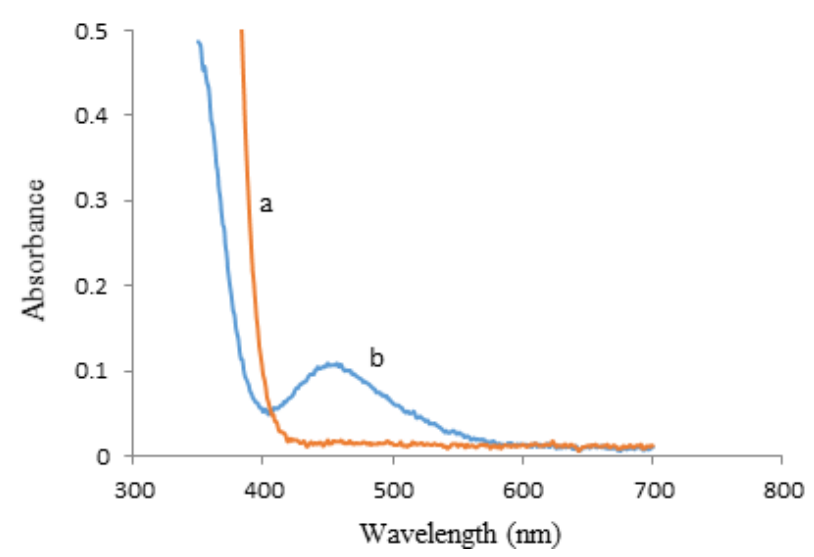

Figure 1. The absorption spectra of (a) diethyldithiocarbamat and (b) its complex with $\mathrm{Cu}(\mathrm{II})$ at $\mathrm{pH} 5$ after DLLME.

\section{Dispersive liquid-liquid microextraction procedure Selection of dispersive and extracting solvents}

In this work, four solvents: methanol, ethanol, tetrahydrofuran and acetonitrile were studied as a dispersive solvent. The selection of the extracting solvent is critical and should meet the following characteristics: (1) it should dissolve the analyte better than water, (2) it should be heavier than water and (3) it should form tiny droplets when it is added to the aqueous solution of analyte along with a dispersive solvent. Almost all of the suitable extracting solvents are chlorinated. In this work, chloroform, carbon tetrachloride and dichloromethane were investigated. For all combinations of dispersive and extracting solvents the absorbance of the $\mathrm{Cu}(\mathrm{II})$-DDTC extracted to the organic phase was measured at $440 \mathrm{~nm}$ against the reagent blank.

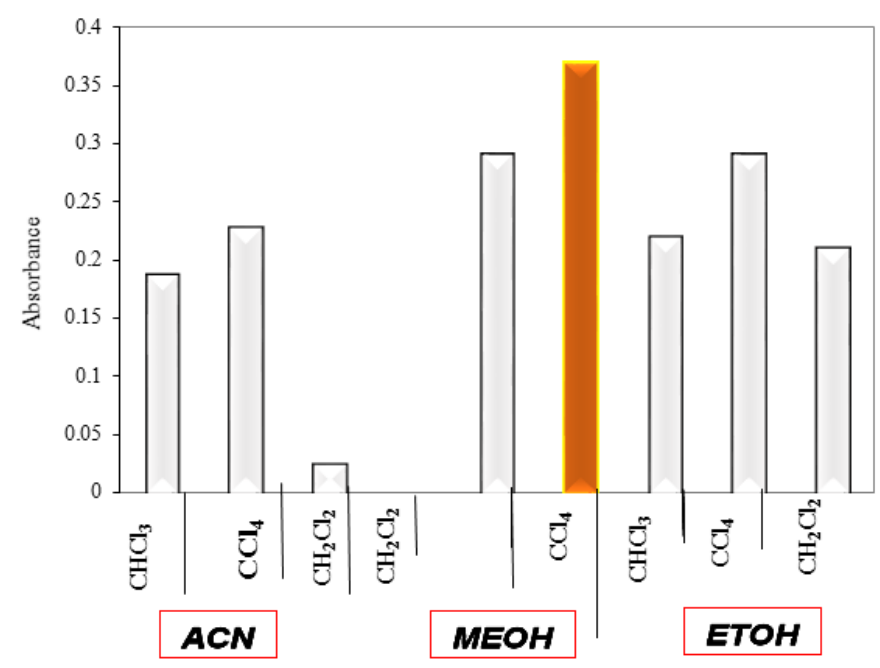

Figure 2. Selection of extracting and dispersive solvents in DLLME. Conditions: Sample, $5 \mathrm{~mL} \mathrm{Cu}$ (II)

$0.1 \mu \mathrm{g} \mathrm{mL}^{-1}$; volume of dispersive solvent, $1 \mathrm{~mL}$; volume of extracting solvent, $200 \mu \mathrm{L}$; buffer,

$1 \mathrm{~mL}$ acetate buffer $(\mathrm{C}=1 \mathrm{M}, \mathrm{pH}=5)$ and DDTC solution, $1 \mathrm{~mL} 0.05 \mathrm{M}$. 
As it is shown in Figure 2, maximum extraction efficiency was obtained for the combination of carbon tetrachloride as extracting solvent with methanol as dispersive solvent. Therefore, the combination of carbon tetrachloride and methanol was selected for further studies.

\section{Dispersive solvent volume}

Methanol as a dispersive solvent in different volumes in the range 0-2.5 $\mathrm{mL}$ along with $200 \mu \mathrm{L}$ carbon tetrachloride as an extracting solvent was used for extraction of $\mathrm{Cu}$ (II)-DDTC complex using the DLLME procedure. The results (Figure 3) show that in the case of $1 \mathrm{~mL}$ methanol the highest absorbance signal was obtained. Therefore, methanol volume of $1 \mathrm{~mL}$ was selected as being optimal for all subsequent experiments.

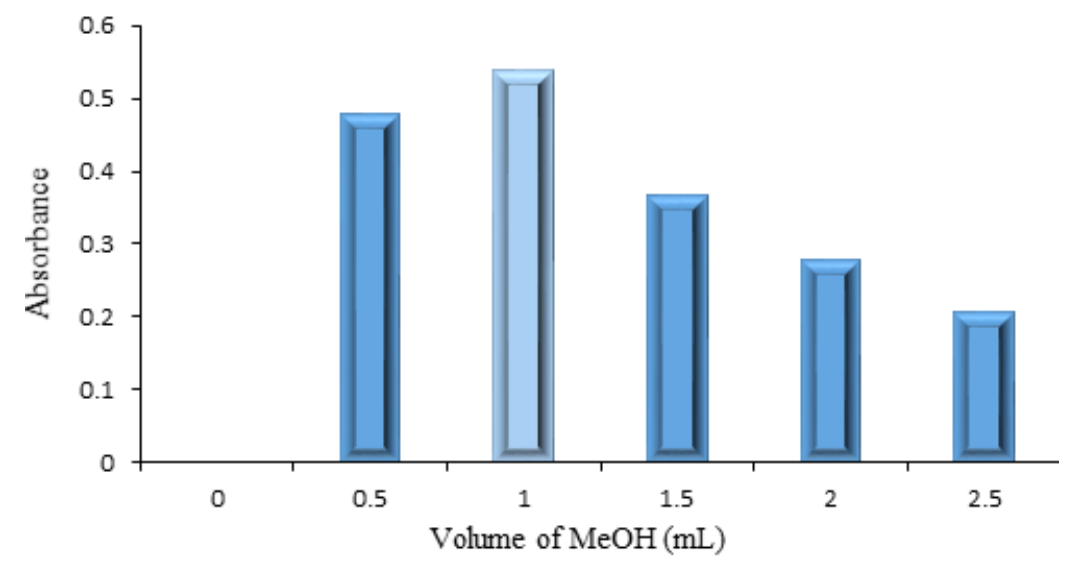

Figure 3. Dispersive solvent volume study. The absorbance of extracted phase vs. dispersive solvent volume. Conditions are the same as Figure 2.

\section{Extracting solvent volume}

Extracting solvent (carbon tetrachloride) volumes on the absorbance and recovery of analyte, in the range of 50-300 $\mu \mathrm{L}$ was investigated. Since the absorbance signal was highest at $200 \mu \mathrm{L}$ of $\mathrm{CCl}_{4}$ as extracting solvent (Figure 4), this was used in further experiments.

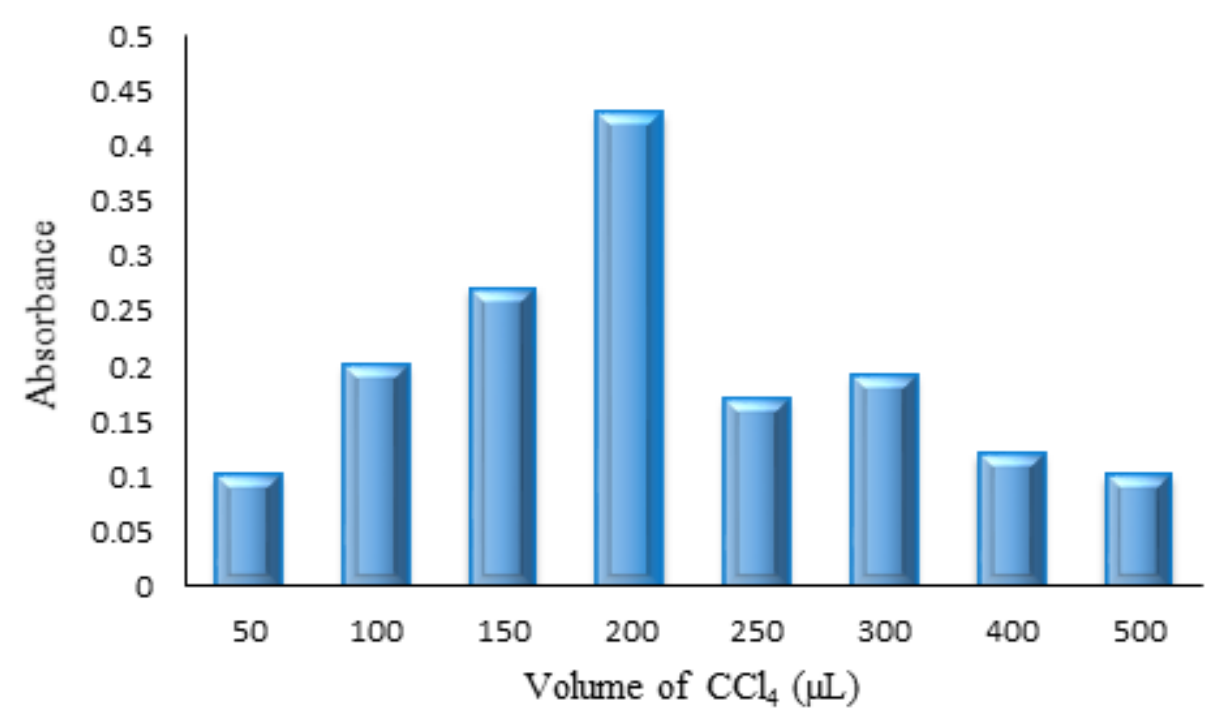

Figure 4. Selection of extracting solvent volume. The absorbance of extracted phase as a function of extracting solvent volume. Conditions are the same as Figure 3. 


\section{Effect of pH}

One of the most important parameters for obtaining high recovery values was the reaction $\mathrm{pH}$ between the ligand and copper. DLLME was performed at different $\mathrm{pH}$ values in the range of 1-11. Figure 5 shows that the absorbance signals increase with an increase in the solution $\mathrm{pH}$ up to a maximum value of 5 and then decreases with further increases in the solution $\mathrm{pH}$. At very alkaline $\mathrm{pH}$ values, the $\mathrm{Cu}$ (II) ions undergo hydrolysis and precipitate in the hydroxide form and measurements at these $\mathrm{pH}$ values mask any result. At acid $\mathrm{pH}$ the decrease in absorbance can be attributed to the protonation of the complexing agent. Thus, there is competition between the protons and the $\mathrm{Cu}(\mathrm{II})$ ions at more acid $\mathrm{pH}$ values. Therefore, $\mathrm{pH} 5$ was selected for all subsequent experiments.

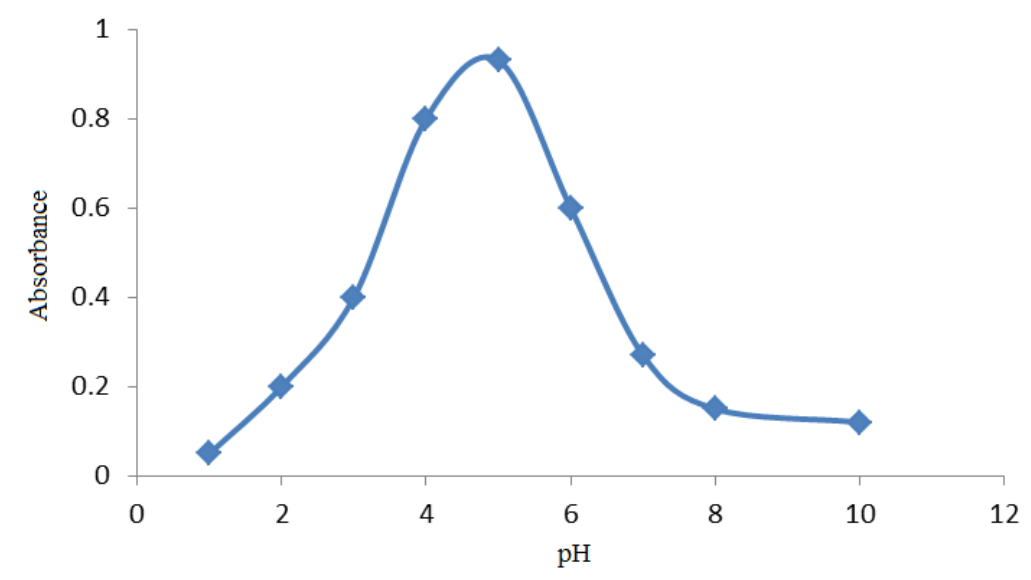

Figure 5. The effect of $\mathrm{pH}$ on the absorbance of Cu-DEDTC complex in extracted phase.

\section{Sample volume}

Different volumes of analyte solution $(5-20 \mathrm{~mL})$ were used to study the effect of sample size with a constant volume of extracting solvent $(200 \mu \mathrm{L})$ and dispersive solvent $(1 \mathrm{~mL})$. As it can be seen in Figure 6, with a large sample size $(20 \mathrm{~mL})$ no sedimented organic phase was obtained. By increasing the sample volume from 5 to $15 \mathrm{~mL}$, the volume of sedimented phase and recovery decreased. Therefore, sample volume of $5 \mathrm{~mL}$ was selected for the following studies.

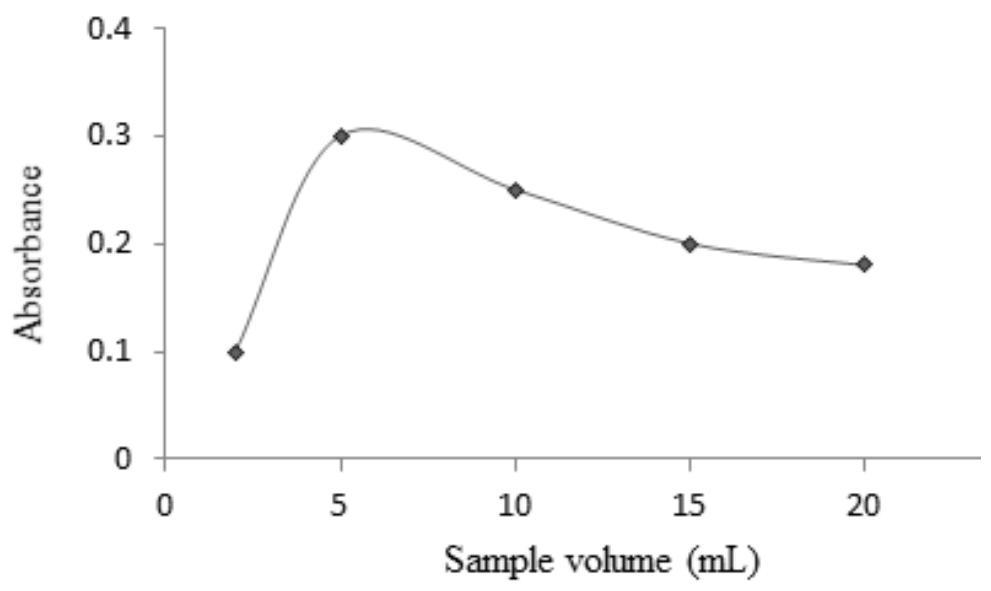

Figure 6. The effect of incubation time prior to centrifuge on the complex formation. 


\section{Study of other parameters}

Other parameters such as DDTC concentration, salting out effect and reaction time were investigated. To determine the suitable ligand concentration, different concentrations of ligand in the range of $10^{-4}-10^{-2} \mathrm{~mol} \mathrm{~L}{ }^{-1}$ was added to $5 \mathrm{~mL}$ of the analyte solution containing $0.1 \mathrm{mg} \mathrm{L}^{-1} \mathrm{Cu}(\mathrm{II})$ at $\mathrm{pH}$ 5. These samples were analyzed according to the procedure. As it is shown in Figure 7, absorbance signals increased up to $10^{-3} \mathrm{~mol} \mathrm{~L}^{-1}$ and then increasing ligand concentration did not influence the extraction recovery. Therefore, a ligand concentration of $10^{-3} \mathrm{~mol} \mathrm{~L}^{-1}$ was selected as being optimal for all subsequent experiments.

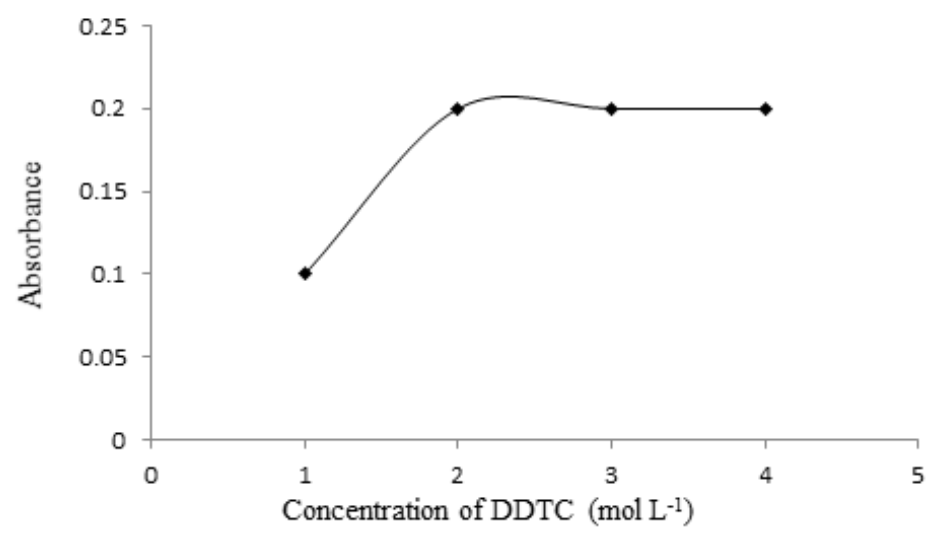

Figure 7. The effect of sample volume on the extraction efficiency at optimum conditions.

Also, the influence of ionic strength on the extraction was studied with sodium chloride as a salting out agent at the range of $0.1-1 \mathrm{~mL}$ of saturated $\mathrm{NaCl}$ solution. The highest absorbance signal was obtained at $0.3 \mathrm{~mL}$ of saturated $\mathrm{NaCl}$ solution (Figure 8). It was found that by increasing sodium chloride, the volume of sedimented phase decreases.

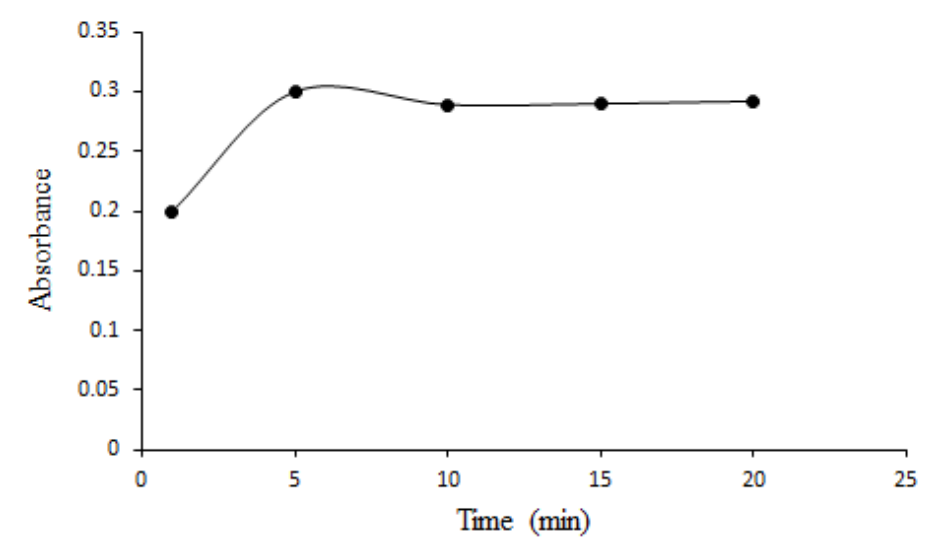

Figure 8. The effect of complexing agent diethyldithiocarbamat on the absorbance of the extracted phase.

Extraction time also was studied over the range 1-20 min (Figure 9). It was defined as the time spent between the addition of extraction solvent (carbon tetrachloride) dissolved in dispersive solvent (methanol) and centrifuging. Since the surface area between the extracting solvent and the aqueous sample is very large, thus the equilibrium state is achieved quickly and time did not affect on the recovery and sediment phase volume. 


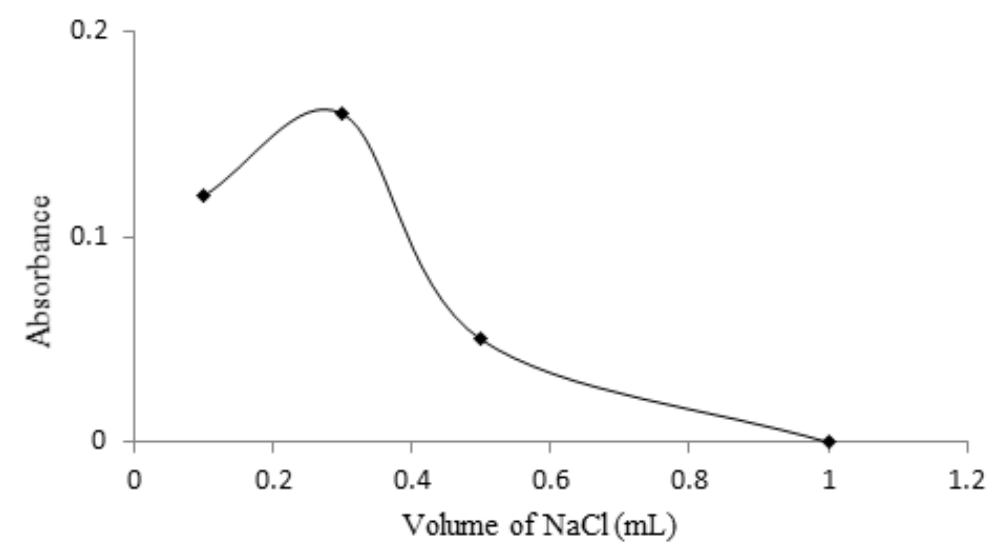

Figure 9. The effect of saturated $\mathrm{NaCl}$ solution on the extraction of $\mathrm{Cu}$ (II)-DDTC complex.

\section{Analytical Characteristics}

Table 1 summarizes the analytical characteristics of the optimized method, including regression equation, linear range, limit of detection, reproducibility, preconcentration, and improvement factors. Under the optimum conditions the calibration graph was linear over the range 0.01 to $0.1 \mu \mathrm{g} \mathrm{mL} \mathrm{m}^{-1}$ of $\mathrm{Cu}$ (II) ion with a correlation coefficient of 0.994 . The limit of detection, defined as $C_{L}=3 S_{B} / m$ (where $S_{B}$ and $m$ are standard deviation of the blank and slope of the calibration graph, respectively) was $8.6 \times 10^{-3} \mu \mathrm{g} \mathrm{mL} \mathrm{L}^{-1}$. Because the amount of $\mathrm{Cu}$ (II) ions in $10 \mathrm{~mL}$ of initial sample solution is measured after DLLME in a final volume of $0.5 \mathrm{~mL}$, the solution is concentrated by a factor of 20 . The improvement factor, defined as the ratio of the slope of the calibration graph for DLLME method to the slope of the calibration graph without preconcentration was 33. Relative standard deviation (RSD) for 7 replicate determinations of $0.08 \mu \mathrm{g} \mathrm{mL}^{-1} \mathrm{Cu}(\mathrm{II})$ was $3.3 \%$.

Table 1. Analytical features of DLLME of $\mathrm{Cu}(\mathrm{II})$ ions.

\begin{tabular}{ll}
\hline Regression equation $^{\mathrm{a}}$ & $\mathrm{Abs}=1.982 \mathrm{C}+0.003$ \\
Regression equation before extraction $^{2 \mathrm{~b}}$ & $\mathrm{Abs}=0.061 \mathrm{C}+0.003$ \\
$\mathrm{R}^{2 \mathrm{~b}}$ & 0.994 \\
Linear range $\left(\mu \mathrm{g} \mathrm{mL}^{-1}\right)$ & $0.01-0.1$ \\
$\mathrm{LOD}\left(\mu \mathrm{gL}^{-1}\right)^{\mathrm{c}}$ & $8.6 \times 10^{-3}$ \\
Repeatability $(\mathrm{RSD})^{\mathrm{d}}$ & 3.3 \\
Concentration factor $^{\mathrm{d}}$ & 20 \\
Improvement factor $^{\mathrm{e}}$ & 33 \\
\hline
\end{tabular}

${ }^{\mathrm{a}}$ Concentration of analyte in $\mu \mathrm{g} \mathrm{mL} \mathrm{m}^{-1}$.

${ }^{\mathrm{b}}$ Squared regression coefficient.

${ }^{\mathrm{c}}$ Limit of detection for $\mathrm{S} / \mathrm{N}=3$.

${ }^{\mathrm{d}}$ Relative standard deviation for 7 replicate determination of $0.08 \mu \mathrm{g} \mathrm{mL}{ }^{-1} \mathrm{Cu}(\mathrm{II})$ ions.

${ }^{\mathrm{e}}$ The ratio of the slope of the calibration graph for the microextraction method to that of the slope of the calibration graph without preconcentration. 


\section{Interference study}

In order to study the selectivity of the proposed method, the effect of various cations and anions on the DLLME of $\mathrm{Cu}$ (II) ions was studied. An ion was considered as interferent, when it caused a variation in the absorbance of the sample greater than $\pm 5 \%$ in comparison with the case in which interfering ion is absent. The results are summarized in Table 2. The results indicate that most of the cations and anions did not interfere even when present 1000-fold excess over analyte. As can be seen most ions studied do not have interfering effect at 1:100 ratio. Only $\mathrm{Fe}$ (III) interfered seriously, which was removed by addition of $5 \%$ triethanolamine (TEA) solution to the sample.

Table 2. Study of interfering ions.

\begin{tabular}{ll}
\hline Interfering ions & $\begin{array}{l}\text { Tolerable concentration } \\
\text { (analyte:interfering ion) }\end{array}$ \\
\hline $\mathrm{Fe}^{3+}$ & $1: 10$ \\
$\mathrm{Co}^{2+}, \mathrm{Ni}^{2+}, \mathrm{Zn}^{2+}, \mathrm{Hg}^{2+}, \mathrm{NO}_{3}^{-}$ & $1: 100$ \\
$\mathrm{Cr}^{3+}, \mathrm{K}^{+}, \mathrm{NO}_{2}^{-}$, EDTA, sodium citrate & $1: 1000$ \\
\hline
\end{tabular}

Concentratio of analyte is $0.08 \mu \mathrm{g} \mathrm{mL}^{-1}$.

${ }^{\mathrm{a}}$ At this ratio no inrerfering effect was observed.

\section{Application of the proposed DLLME method for determination of $\mathrm{Cu}(\mathrm{II})$ in blood serum}

The extraction of the $\mathrm{Cu}(\mathrm{II})$ ions was conducted according to the procedure. For removal matrix effect in the serum sample, standard addition method was applied. The concentration of $\mathrm{Cu}$ (II) in blood serum was determined from intercept of the standard addition plots. The result is shown in Figure 10. The concentration of $4.5 \times 10^{-2} \mu \mathrm{g} \mathrm{mL}^{-1}$ was obtained for $\mathrm{Cu}$ (II) in the serum sample 1 . Two other human plasma samples were analyzed and the results were presented in Table 3. The results indicate indicate that the method can be successfully applied to recover $\mathrm{Cu}(\mathrm{II})$ ions in serum samples.

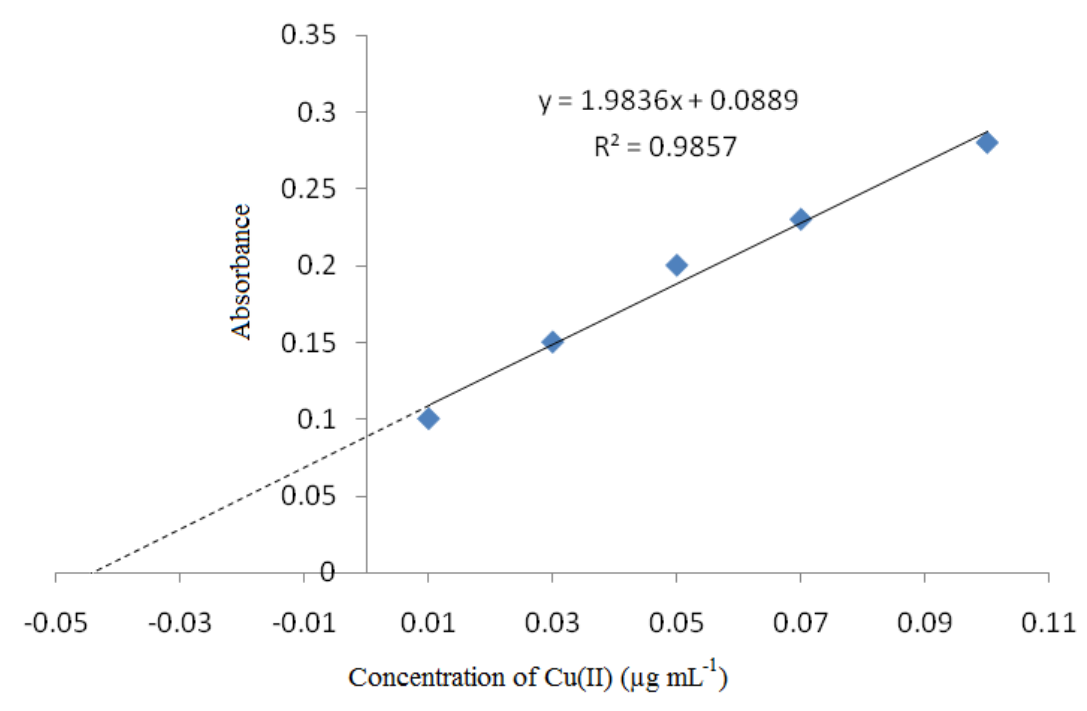

Figure 10. Standard addition plot of $\mathrm{Cu}(\mathrm{II})$ in human blood serum sample. 
Table 3. Determination of $\mathrm{Cu}(\mathrm{II}))$ in the plasma samples by the proposed method.

\begin{tabular}{lccc}
\hline Samples & Added $\left(\mathrm{ng} \mathrm{mL}^{-1}\right)$ & Found $\left(\mathrm{ng} \mathrm{mL}^{-1}\right)$ & Recovery $(\%)$ \\
\hline Sample 1 & 0 & 45 & - \\
& 40 & 97 & 105 \\
Sample 2 & - & $<$ LOD & - \\
& 40 & 41.2 & 103 \\
& 60 & 59 & 98.3 \\
Sample 3 & - & $<$ LOD & - \\
& 40 & 39.4 & 98.5 \\
& 60 & 57 & 94.5 \\
\hline
\end{tabular}

\section{Conclusion}

A dispersive liquid-liquid microextraction for the preconcentration and spectrophotometric determination of copper(II) was used. The proposed method was based on the complexation reaction of $\mathrm{Cu}(\mathrm{II})$ with DDTC from aqueous phase into the fine droplets of extraction solvent. Concentration factor and improvement factor for the target analyte were obtained about 20 and 33, respectively. The proposed extraction method was used for the quantitation of $\mathrm{Cu}$ (II) ions in blood serum sample. The method is simple, efficient and very rapid and it uses extracting solvent at a $\mu \mathrm{L}$ level.

\section{References}

1- D. L. de Romãna, M. Olivares, R. Uauy, M. Araya, J Trace Elem Med Biol, 2011, 25, 3-13.

2- WHO, Copper in drinking-water: Background document for development of WHO guidelines for drinking-water quality. Geneva: World Health Organization (WHO/SDE/ WSH/03.04/88), 2004.

3- USEPA, Lead and copper monitoring and reporting guidance for public water systems. EPA-816-R-02-009. Washington, DC: Ground Water and Drinking Water Division, Water Programs, US Environmental Protection Agency, 2002.

4- N. J. K. Simpson, Solid Phase Extraction: Principles, Techniques and Application, Marcel Dekker, USA, 2000.

5- K. Wieszczycka, M. Kaczerewska, M. Krupa, A. Parus, A. Olszanowski, Sep. Purif. Technol., 2012, 95, 157-164.

6- S. H. Chang, T. T. Teng, N. Ismail, Water Air Soil Pollut., 2011, 217, 567-576.

7- D. Kara, M. Alkan, Microchem. J., 2002, 71, 29-39.

8- M. A. Farajzadeh, M. Bahram, S. Zorita, B. Ghorbani Mehr, J. Hazard. Mater., 2009, 161, 1535-1543.

9- P. Liang, J. Yang, J. Food Compos. Anal., 2010, 23, 95-99.

10- M. Bahram, S. Khezri, Anal. Methods, 2012, 4, 384-393.

11- A. B. Tabrizi, J. Hazard. Mater., 2007, 139, 260-264.

12- E. L. Silva, P. S. Roldanb, M. F. Giné, J. Hazard. Mater., 2009, 171, 1133-1138.

13- E. M. Soliman, H. M. Marwani, H. M. Albishri, Environ. Monit. Assess, 2013, 185, 10269-10280.

14- S. Chen, C. Liu, M. Yang, D. Lu, L. Zhu, Z. Wang, J. Hazard. Mater., 2009, 170, 247-51. 
15- N. Farnad, K. Farhadi, N. H. Voelcker, Water Air Soil Pollut., 2012, 223, 3535-3544.

16- Q.M. Li, X.H. Zhao, K. Jiang, G.G. Liu, Chinese Sci. Bull., 2007, 52, 65-70.

17- A. Smara, R. Delimi, C. Poinsignon, J. Sandeaux, Sep. Purif. Technol., 2005, 44, 271-277.

18- H. Chen, J. Jin, Y. Wang, Anal. Chim. Acta, 1997, 353, 181-188.

19- I. Komjarova, R. Blusa, Anal. Chim. Acta, 2006, 576, 221-228.

20- M. Rezaee, Y. Assadi, M.R. Milani Hosseini, E. Aghaee, F. Ahmadi, S. Berijani, J. Chromatogr. A, 2006, 1116, 1-9.

21- M. Rezaee, Y. Yamini, M. Faraji, J. Chromatogr. A, 2010, 1217, 2342-2357.

22- A. Asghari, M.Ghazaghi, M. Rajabi, M. Behzad, M. Ghaedi, J. Serb. Chem. Soc., 2014, 79, 63-76.

23- R. E. Rivas, I. Lopez-Garcia, M. Hernandez-Cordoba, Microchim. Acta, 2009, 166, 355-361.

24- E. Stanisz, A. Zgoła-Grześkowiak, Talanta, 2013, 115, 178-183.

25- M. Amirkavei, S. Dadfarnia, A. M. Haji Shabani, Quim. Nova, 2013, 36, 63-68.

26- D. Kantürer Acar, D. Kara, Water Air Soil Pollut., 2014, 225, 1864-1872.

27- M. A. Farajzadeh, M. Bahram, B. Ghorbani Mehr, J. A. Jonsson, Talanta, 2008, 75, 832-840.

28- A. N. Anthemidis, K. -I.G. Ioannou, Talanta, 2009, 79, 86-91.

29- H. Karimi, M. Ghaedi, A. Shokrollahi, H. R. Rajabi, M. Soylak, B. Karami, J. Hazard. Mater., 2008, 151, 26-32.

30- Y. Yamini, M. Rezaee, A. Khanchi, M. Faraji, A. Saleh, J. Chromatogr. A, 2010, 1217, 2358-2364.

31- B. Horstkotte, M. Alexovič, F. Maya, C. M. Duarte, V. Andruch, V. Cerdá, Talanta, 2012, 99, 349-356.

32- M. N. Uddin, Md. A. Salam, M. A. Hossain, Chemosphere, 2013, 90, 366-373.

33- K. Kocot, B. Zawisza, R. Sitko, Spectrochim. Acta Part B, 2012, 73, 79-83.

34- A. Hulanicki, Talanta, 1967, 14, 1371-1392.

35- X. Wen, Q. Yang, Z. Yan, Q. Deng, Microchem. J, 2011, 97, 249-254. 